\title{
CRACK GROWTH PATH SIMULATION IN A CEMENT MANTLE OF THR USING CRACK BOX TECHNIQUE
}

\author{
AbDelkader Boulenouar \\ Djillali Liabes University of Sidi Bel-Abbes, Mechanical Engineering Department, Laboratory of Materials and Reactive \\ Systems, City Larbi Ben Mhidi, Algeria \\ e-mail:aek_boulenouar@yahoo.fr \\ NADJET BENDIDA \\ Djillali Liabes University of Sidi Bel-Abbes, City Larbi Ben Mhidi, Algeria \\ e-mail: nabendida@gmail.com
}

\begin{abstract}
A numerical method for 2D LEFM crack propagation simulation in a cement mantle of the total hip replacement (THR) is presented. This work is based on the implementation of the displacement correlation technique (DCT) and the maximum circumferential stress (MCS) theory in a finite element code, using the Ansys Parametric Design Language (APDL). At each crack increment length, the crack direction angle is evaluated as a function of stress intensity factors (SIFs). The crack box technique is investigated for crack propagation simulation. The advantage of this technique is facilitation of the automatic remeshing of the structure during crack extension. In this paper, we analyzed the mechanical behavior of cracks initiated in the cement mantle by evaluating the SIFs. The effect of the cavities and the initial crack directions on the crack growth path has been highlighted.
\end{abstract}

Keywords: stress intensity factor, crack propagation, orthopedic cement, total hip replacement

\section{Introduction}

The mechanical resistance of the total hip prosthesis depends primarily on the nature of cement used. The principal role of cement is to ensure a good implant-bone adhesion and to minimize the transfer of load toward the bone. Under the effect of mechanical loading, cement must be able to resist the initiation and propagation of a crack being able to lead to its ruin and, consequently, the unsealing of the prosthesis.

The presence of a defect in the cement during mixing can locally lead to a region of stress concentrations producing a possible fracture of cement and, consequently, the loosening of the prosthetic cup. Almost, there are three kinds of defects: porosities, inclusions and cracks.

It is known that cracks are the most dangerous defects because of the presence of stress intensity on their front. Three kinds of cracks can be identified in orthopedic cement (Bachir Bouiadjra et al., 2007; Achour et al., 2010; Benbarek et al., 2009):

- cracks initiated at porosities (Fig. 1),

- cracks initiated during cement withdrawal,

- cracks initiated at the junction between the bone and cement or between the cement and cup.

In literature, several numerical works have been realized to study the crack path prediction in orthopedic cement: Benouis et al. (2015) presented a numerical analysis of cracking trajectory in cement of reconstructed acetabulum. The crack direction was determined using the strain energy 


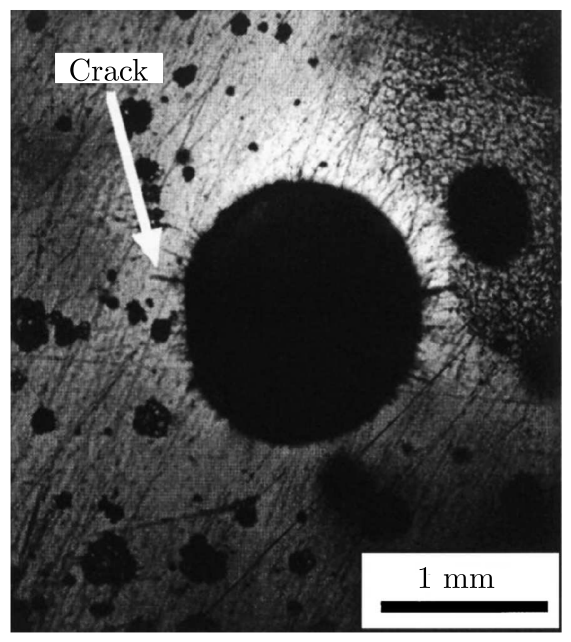

Fig. 1. Photographic image of a crack in the cement layer. Emanating from a large pore, other pores of various sizes are also present (ANSYS, 2008; McCormack and Prendergast, 1999)

density approach and the displacement extrapolation technique. Benbarek et al. (2013) presented a numerical modeling of the crack path in the cement mantle. The maximum circumferential stresses criterion was investigated to predict the direction of crack emanating from a micro-void in the cement layer. Boulenouar et al. (2016) investigated the different crack growth criteria to compare the propagation path of the crack in the orthopedic cement of the total hip replacement. Kim et al. (2008) determined the specific fracture mechanics response of cracks that initiated at the stem-cement interface and propagated into the cement mantle. Oshkour et al. (2013) investigated the X-FEM to analyze the behavior of the internal circumferential cracks located in the cement layer of the cement-prosthesis interface during the main phases of the gait cycle. Ouinas et al. (2012) made a numerical study on the femoral part based on the dynamic loading effect, the crack propagation in the orthopedic cement, to describe the mechanical behavior of cracks in the total hip prosthesis THP. Benouis et al. (2018) investigated the 3D-FE method to analyse the behavior of cracks initiated in the cement binding the femoral stem to the bone. That behavior was studied in terms of changes in the SIFs under modes I, II and III. Bouziane et al. (2013) showed that the stress intensity factor evaluated for a crack emanating from an inclusion was higher than the crack emanating from a cavity. Flitti et al. (2010) analyzed the propagation criteria of cracks to predict the failure behavior of cemented hip prostheses under the monotonic loading conditions. This analysis was carried out on various zones of cement along the bone, namely the proximal, medial and distal positions. Benouis et al. (2018) investigated the 3D-FE method to analyse the distribution of equivalents stress of von Mises around a cavity located in the bone cement polymethylmethacrylate (PMMA). Results showed that the micro-porosity located in the proximal and distal zone of the prosthesis was subject to higher stress field. Taylor et al. (2003) used the analytical and numerical methods to predict damage of a bone.

The making use of crack propagation laws based on stress intensity factor range is the most successful engineering application of fracture mechanics. The SIFs are very important parameters in fracture analysis. These factors define the stress field close to the crack tip and provide fundamental information on how the crack is going to propagate. The use of this factor can be an effective tool to analyse the fracture behavior of cracks in orthopedic cement.

In linear elastic fracture mechanics, various fracture criteria for cracks subjected to a mixed mode loading have been introduced for determination of the propagation direction. These criteria can be categorized on the basis of the critical parameter on which the criterion is defined. These parameters might be the critical value of stress, energy or strain. Griffith (1921) was the first to propose a crack initiation criterion based on energy. On the other hand, Erdogan and Sih (1963) 
were first to propose a crack propagation criterion in terms of $\sigma_{\theta 0}$, known as the Maximum Circumferential Stress (MCS) criterion. Later, Sih $(1973,1974)$ used the strain as a critical parameter in order to propose the minimum strain energy density $(S)$ criterion. Similar to Sih, Theocaris et al. $(1982 \mathrm{a}, \mathrm{b})$ used the strain as a critical parameter to propose the maximum dilatational strain energy $(T)$ criterion. On the other hand, Kong et al. (1995) proposed the maximum triaxial stress $(M)$ criterion which uses the stress as the critical parameter.

The aim of this paper is to present numerical modeling of the crack propagation trajectory in an orthopedic cement mantle of the total hip replacement (THR). Using the Ansys Parametric Design Language (APDL) (2009), the direction crack is evaluated as a function of the displacement correlation technique and the maximum circumferential stress theory. The FE technique is employed to carry out this study. The effect of cavities and the initial crack direction on the crack path in orthopedic the cement is investigated.

\section{Computation of fracture parameters}

\subsection{Stress intensity factors}

In a linear elastic fracture problem, the prediction of crack growth and crack direction are determined by the SIFs. Several methods have been proposed to numerically estimate SIFs using FEM such as the $J$-integral (Rice, 1986), virtual crack closure method (VCCM) (Rybicki and Kanninen, 1977), displacement extrapolation technique (DET) (Boulenouar et al. 2013a,b, 2014; Benamara et al. 2017a,b), displacement correlation technique (DCT) (Lim et al., 1992). In this study, the nodal displacement correlation technique, which was first introduced by Shih et al. (1976), is implemented. The SIFs for the mixed mode problems can be calculated as

$$
\begin{aligned}
& K_{I}=\frac{G}{k+1} \sqrt{\frac{2 \pi}{L}}\left[4\left(v_{b}-v_{d}\right)-\left(v_{c}-v_{e}\right)\right] \\
& K_{I I}=\frac{G}{k+1} \sqrt{\frac{2 \pi}{L}}\left[4\left(u_{b}-u_{d}\right)-\left(u_{c}-u_{e}\right)\right]
\end{aligned}
$$

where $G$ is the shear modulus, $L$ is the element length, $k$ is defined as $k=(3-4 \nu)$ for plane strain and $k=(3-\nu) /(1+\nu)$ for plane stress, $\nu$ is Poisson's ratio.

The $u$ and $v$ are displacement components in the $x$ and $y$ directions, respectively, where the subscripts indicate their positions as shown in Fig. 2.

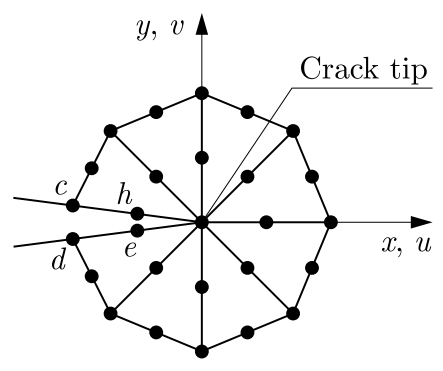

Fig. 2. Nodes around the crack tip for calculation of the SIFs

According to Barsoum (1974), to have a more precise displacement and stress results by FE analysis, singular elements can be used at the vicinity of the crack tip. These triangular quarter point elements (Fig. 2) also help one to obtain a good representation of the stress field around the crack-tip. 


\subsection{Crack path direction}

In order to simulate crack propagation under linear elastic conditions, the crack path direction $\theta$ must be determined. There are several methods used to predict the direction of the crack trajectory such as the maximum circumferential stress theory, the maximum energy release rate theory and the minimum strain energy density theory. The maximum circumferential stress theory asserts that, for isotropic materials under a mixed-mode loading, the crack will propagate in a direction normal to the maximum tangential tensile stress. In polar coordinates, the tangential stress is given by

$$
\sigma_{\theta}=\frac{1}{\sqrt{2 \pi r}} \cos \frac{\theta}{2}\left(K_{I} \cos ^{2} \frac{\theta}{2}-\frac{3}{2} K_{I I} \sin \theta\right)
$$

The direction normal to the maximum tangential stress can be obtained by solving $d \sigma_{\theta} / d \theta=0$ for $\theta$. The nontrivial solution is given by

$$
K_{I} \sin \theta+K_{I I}(3 \cos \theta-1)=0
$$

which can be solved as

$$
\theta=2 \arctan \left[\frac{1}{4} \frac{K_{I}}{K_{I I}} \pm \frac{1}{4} \sqrt{\left(\frac{K_{I}}{K_{I I}}\right)^{2}+8}\right]
$$

\section{Geometrical model and material properties}

Figure 3a shows the geometrical model used in this study. It is taken from our previous study (Benouis et al., 2016). The prosthesis is devised in three zones: proximal, median and distal and two parts: interior (right part) and exterior (left part). The contact between the cement and the stem and between the bone and the cement is considered as fully bounded.

(a)

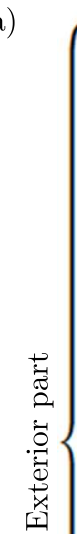

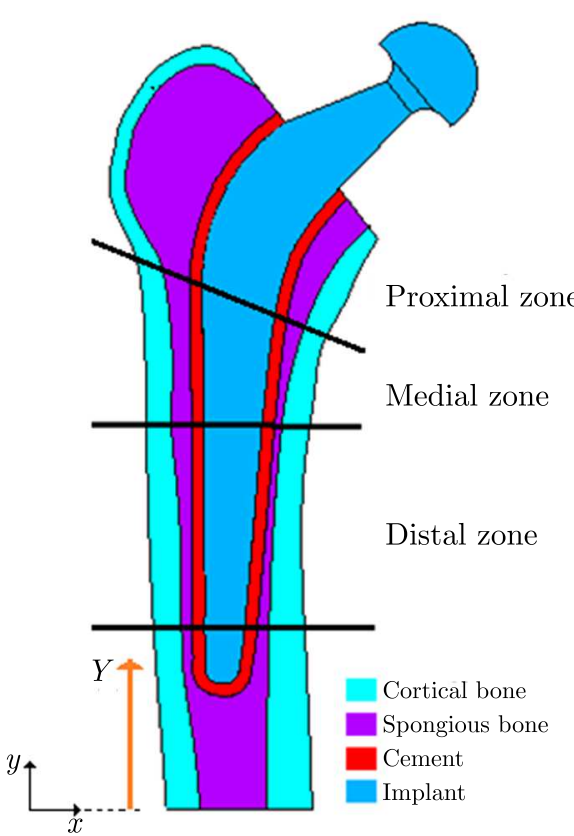

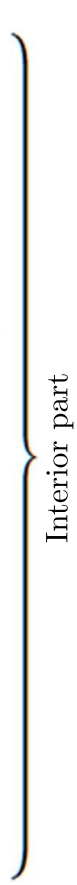

b)

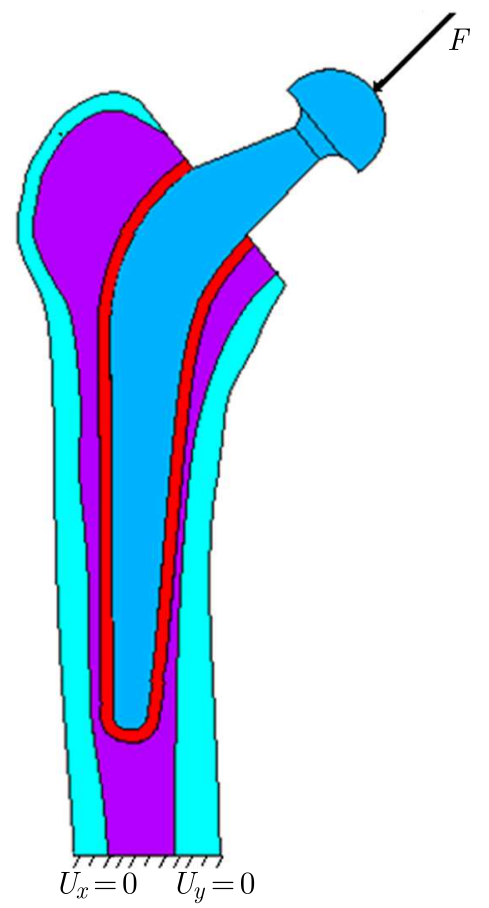

Fig. 3. (a) Geometrical model, (b) boundary conditions 
The mechanical properties of the total hip prosthesis components are given in Table 1. The cortical bone, spongious bone, orthopedic cement and the stem are all considered as elastic isotropic materials.

Table 1. Materials properties (Sahli, 2014)

\begin{tabular}{|l|c|c|}
\hline \multicolumn{1}{|c|}{ Materials } & $\begin{array}{c}\text { Young modulus } \\
E[\mathrm{MPa}]\end{array}$ & $\begin{array}{c}\text { Poisson ratio } \\
\nu[-]\end{array}$ \\
\hline \hline Cortical bone & 17000 & 0.3 \\
\hline Spongious bone & 2000 & 0.3 \\
\hline Bone cement & 2300 & 0.33 \\
\hline Metallic implant & 219999 & 0.3 \\
\hline
\end{tabular}

Figure $3 \mathrm{~b}$ shows boundary conditions acting on the geometrical model. The boundary conditions imposed are taken from the previous work (Benouis et al., 2016). $u_{x}$ and $u_{y}$ indicate the displacements in the $x$ and $y$ directions, respectively. In order to approach the reality, a force $F=2400 \mathrm{~N}$ is applied to the centre of the femoral head (Fig. 3a). It corresponds to a three times of average weight of a man $(80 \mathrm{~kg}$ ) (Bachir Bouiadjra et al., 2007). These conditions of loading are considered as the extreme case of the effort which the prosthesis can support. It is the force which the man can exert on only one support at the time of rise on a staircase (Leroy, 1991).

\section{Finite element model}

In this Section, the initial crack of length $a=0.2 \mathrm{~mm}$ emanating from the microcavity in the cement layer is considered (Fig. 4a). The FE ANSYS Mechanical APDL has been investigated for the modeling of the two-dimensional (2D) problem using plane stress state conditions (Benouis et al., 2016). Figure 4b shows a typical FE model used in this study.

In order to simulate the stress concentration at the crack tip more accurately, the displacement correlation technique (DCT) subroutines are used, the mesh is skewed at the crack tip and the 8-noded quadrilaterals are collapsed to triangles around the crack tip (Fig. 4c). The mesh discretization consists of 19309 elements and 39082 nodes.

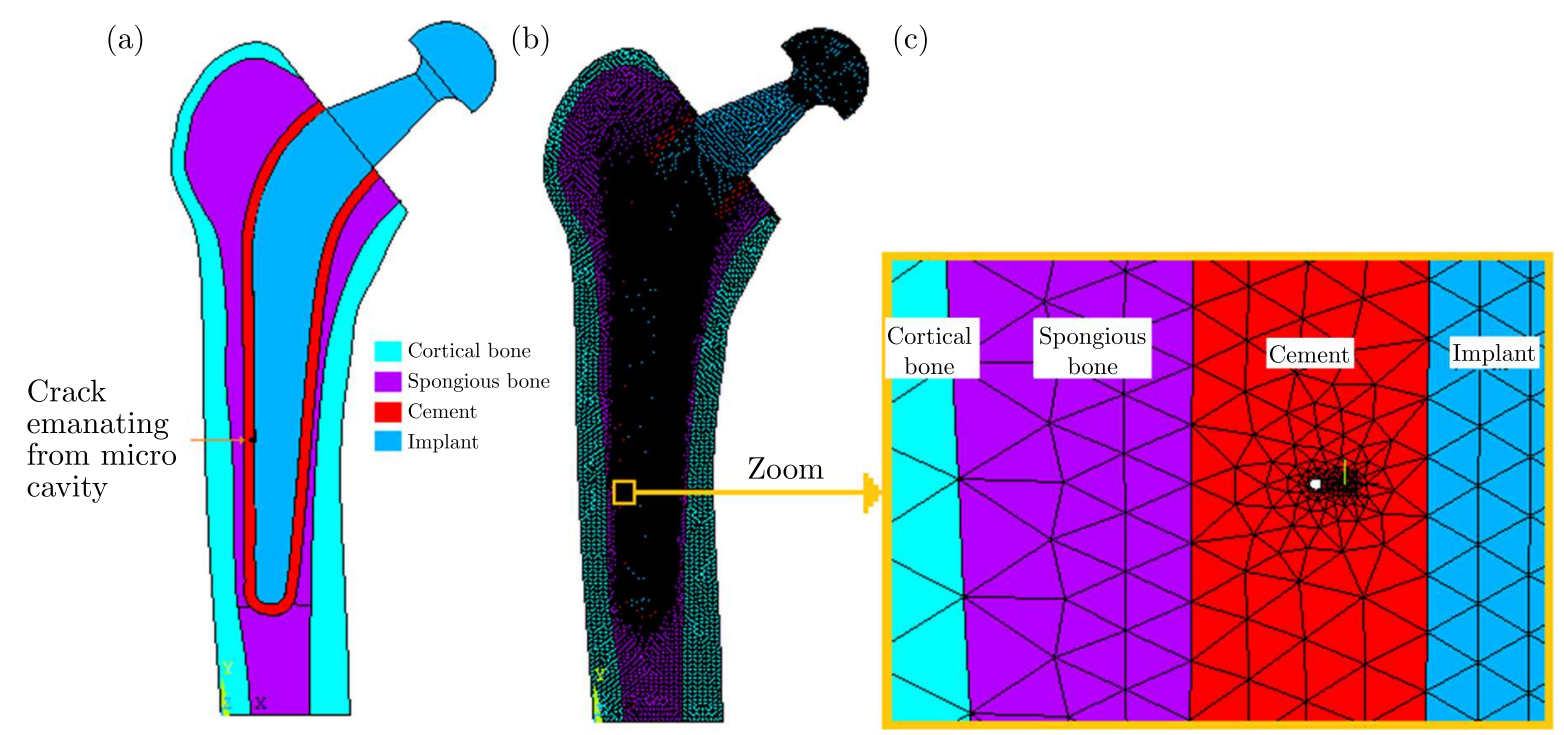

Fig. 4. (a) Crack in the cement layer, (b) mesh model and (c) special elements used for DCT 


\section{Automated methodology for the modeling of the crack extension}

In this paper, the FE ANSYS Mechanical APDL code has been used for creating a program to simulate the mixed-mode crack extension in the orthopedic cement mantle. The displacement correlation method and the MCS approach have been implemented to determine the SIFs and the crack direction at each increment $\Delta a$. Figure 5 shows the flowchart of the study.

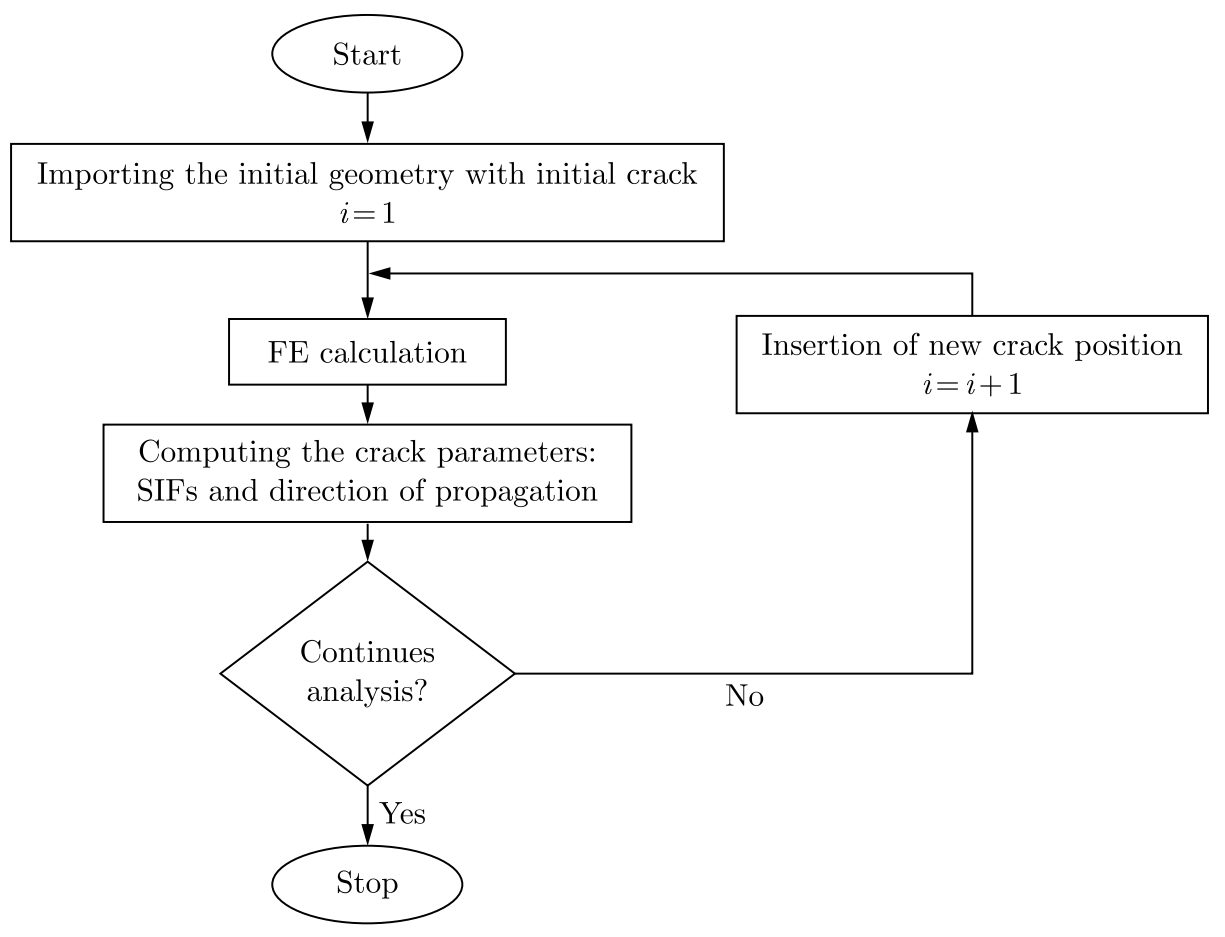

Fig. 5. A flowchart based on the MCS approach and FE analysis

\section{Analysis and results}

This section aims at the FEM analysis of the fracture behavior of cement fixing the implant at the bone. The field of this analysis extends on various zones of cement layers (proximal, median and distal), on the exterior and interior sides of the femur.

We clearly show the effect of the crack position and its orientation in the cement on variations of the SIFs at the crack tip.

To make this study, a crack of length $a=200 \mu \mathrm{m}$ emanating from a microvoid of radius $R_{\text {cav }}=50 \mu \mathrm{m}$ is assumed to exist in the cement layer (Fig. 6).

\subsection{Effect of the crack displacement}

\subsubsection{Exterior side of the femur}

The crack considered is assumed to move vertically from the distal zone towards the proximal zone. The results obtained are illustrated in Figs. 7a and 7b. These show respectively the variations of the stress intensity factors $K_{I}$ and $K_{I I}$ for two crack tip positions $\left(\alpha=0^{\circ}\right.$ and $\left.180^{\circ}\right)$. The curves are plotted for different crack positions $(Y)$ in the cement layer.

The results obtained show that:

1) The two positions of the crack tip $\left(\alpha=0^{\circ}\right.$ and $\left.180^{\circ}\right)$ almost lead to the same values of the SIFs $K_{I}$ and $K_{I I}$. The difference in the SIFs between the two positions is not very marked. 
(a)

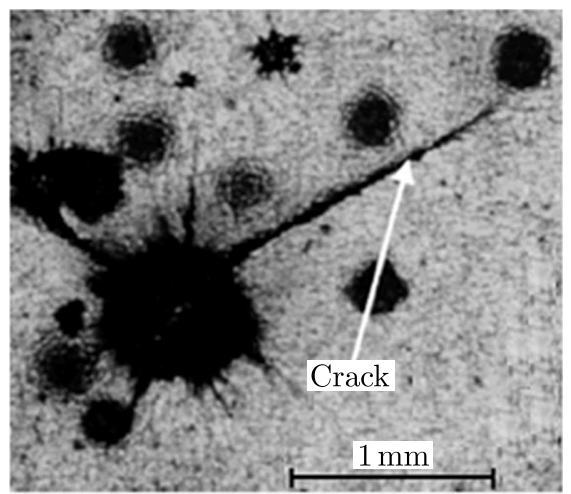

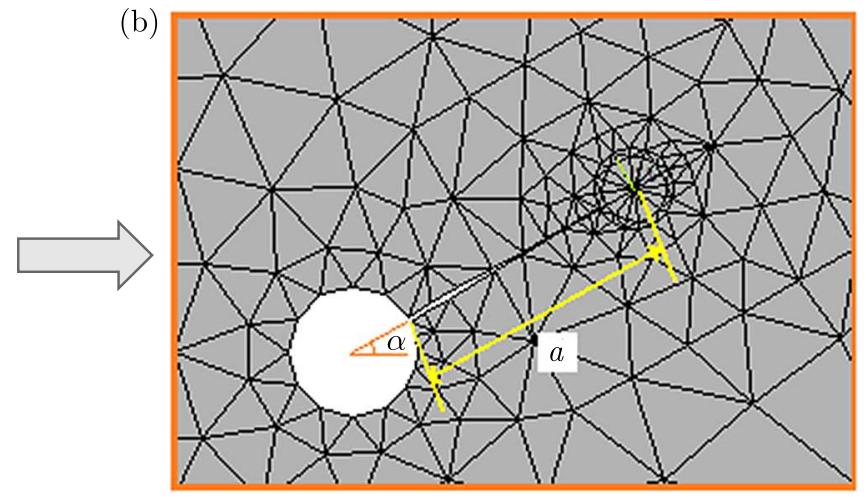

Fig. 6. (a) Cracks in the cement layer observed by transmitted light (Benbarek et al., 2009), (b) FE analysis

(a)

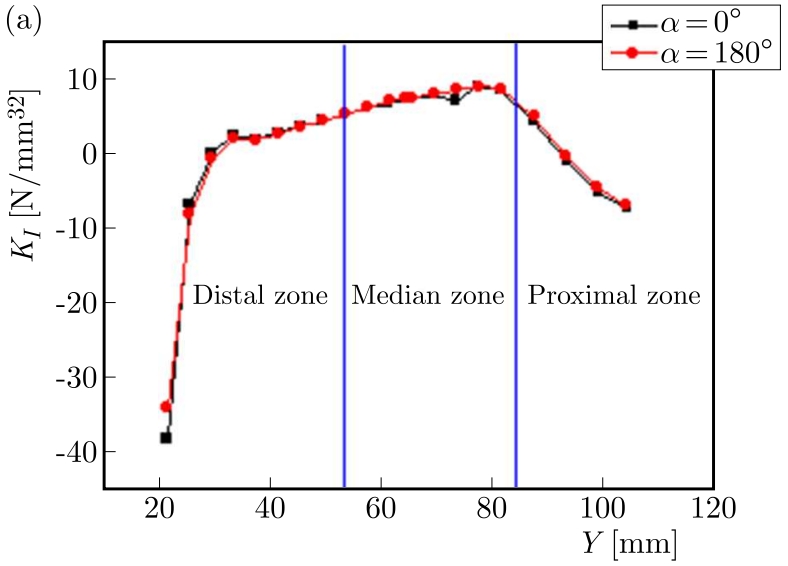

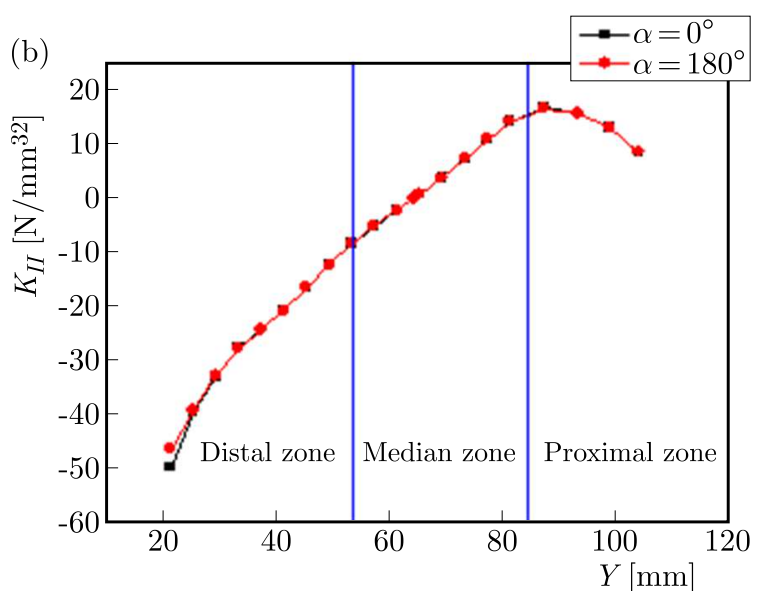

Fig. 7. Variation of SIFs vs. height $Y$ (femur exterior side): (a) variation of $K_{I}$, (b) variation of $K_{I I}$

2) The stress intensity factor depends on the position of the cracked cement. The displacement of the crack from the distal zone to the median zone leads to an increase in the values of the SIFs. The maximum values of $K_{I}$ are reached in the median zone near the proximal zone. In the latter zone, the SIFs $K_{I}$ increase in the absolute value when the crack approaches the femoral head of the bone. Such a crack, characterized by a negative stress intensity factor, is energetically stable and cannot develop.

3) The evolution of the SIFs is also observed under mode II (Fig. 7b). We first observe that the most important values of the SIFs are at the bottom of the proximal zone close to the median zone, where the compressive and tension stresses compensate, thus generating high shear stresses (Bhambri and Gilbertson, 1996; Hunga et al., 2004; Belhouari et al., 2007). The latter are the main cause of the increase in the stress intensity factor in this prosthesis region. As one moves away from this zone, the tangential stresses decrease in intensity, thus leading to a decrease in the stress intensity factor. This shows that in the area delimiting the zone proximal to the median area, the cement presents a risk of damage by a sudden rupture. In other words, the cement may rupture by the opening mode in the distal zone and by shearing its lips in the adjacent medial-proximal part.

\subsubsection{Interior side of the femur}

In the same way, we illustrate in Figs. $8 \mathrm{a}$ and $8 \mathrm{~b}$, respectively, the variations of the stress intensity factors under mode I and mode II loadings for two positions of the crack tip and in the three zones of the prosthesis on the interior side of the femur. From these figures, we observe that: 
1) In the three zones, the two positions of the crack tip $\left(\alpha=0^{\circ}\right.$ and $\left.180^{\circ}\right)$ lead almost to the same values of the stress intensity factors $K_{I}$ and $K_{I I}$.

2) In the distal zone, the stress intensity factor $K_{I}$ increases in the absolute value, stabilizes in the median zone and then increases in the absolute value in the proximal zone (Fig. 8a). This behavior is observed for two positions of the crack tip tip $\left(\alpha=0^{\circ}\right.$ and $\left.180^{\circ}\right)$.

3) The negative values of the SIF $K_{I}$ in the three regions of the cement layer clearly show that in the inner part the cement is subjected to compression. The most important compression stresses are strongly localized in the distal zone of the prosthesis. It is in this part that the SIF is most marked (Belhouari et al., 2007; Achour, 2006; Achour et al., 2007; Flitti et al., 2010).

4) Under mode II, the highest SIFs $K_{I I}$ are obtained in the medial and proximal zones of the cement layer (Fig. 8b).

5) The results illustrated in Figs. 8a and 8b show, depending on the solicitation mode of the prosthesis, that a crack initiated in the cement presents a risk of crack propagation under mode II. The negative values of the SIFs $K_{I}$ explain this behavior.
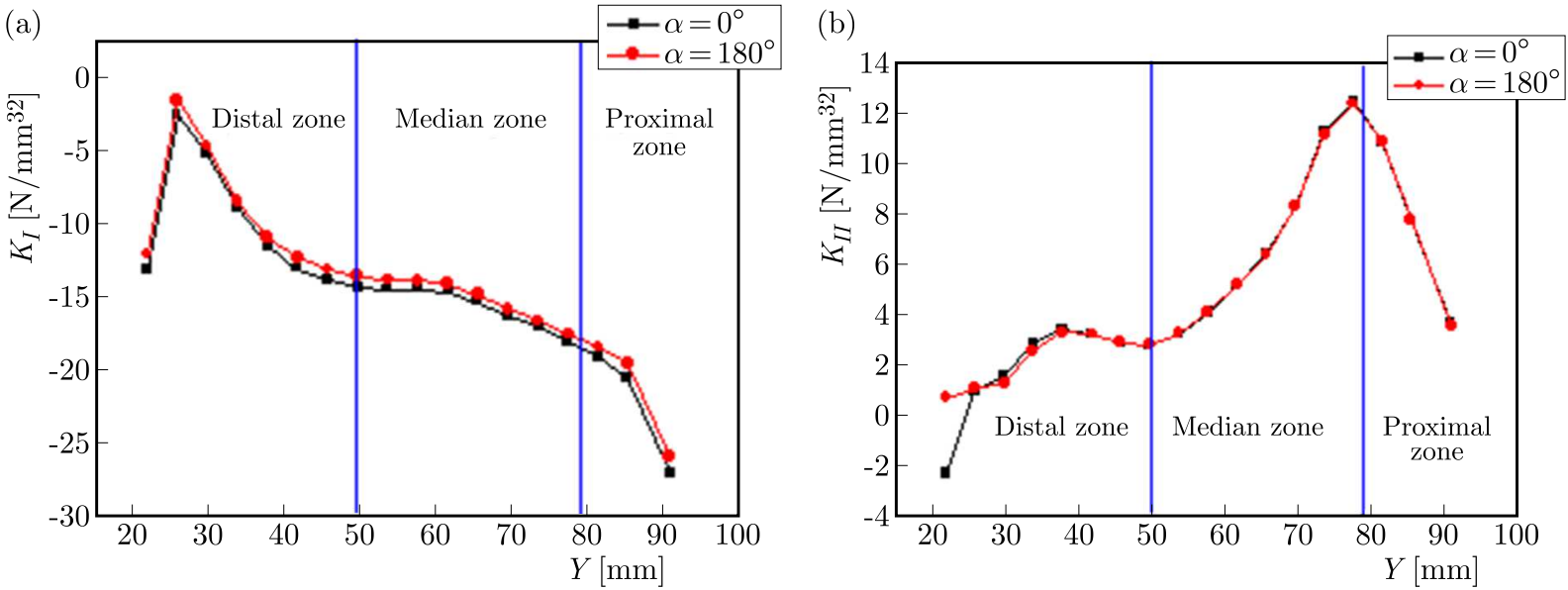

Fig. 8. Variation of SIFs vs. height $Y$ (Femur interior side): (a) variation of $K_{I}$, (b) variation of $K_{I I}$

\subsection{Crack propagation simulation}

In the case of a cracked structure under a mixed mode loading, the crack does not propagate in a straight line, and it is necessary to determine the direction of crack trajectory. Many criteria have been proposed to determine the kinking angle of the crack propagation. Once this particular angle, the crack propagates by a distance $\Delta a$. The smaller this distance is the closer is to the exact solution. Most authors prefer to set $\Delta a$ as a user setting, preferably small (Boulenouar et al., 2013a). For our part, to determine whether the criterion used in this study provides a good final crack trajectory, we have performed our numerical calculation with a succession of crack increment length $\Delta a=20 \mu \mathrm{m}$.

In this Section, we propose to study the propagation path for the crack position $Y \approx 46.48 \mathrm{~mm}$ and for several inclination angles $\alpha$. We recall that the determination of the SIFs $K_{I}$ and $K_{I I}$ and the path propagation of these crack orientations are carried out under plane stress conditions with the same boundary conditions.

For the purpose of simulating the crack propagation, a technique of the crack box around the crack tip has been introduced in the Ansys code. The advantage of the crack box is facilitation of the automatic remeshing of the structure during automatic crack propagation and keeping the same numbering of the nodes on singular elements around the crack tip. The conservation of 
the nodes will allow us to automatically compute the SIFs at each crack propagation increment, using the DCT technique and MCS approach. Figure 9 illustrates an example of the use of the crack box technique during crack extension.
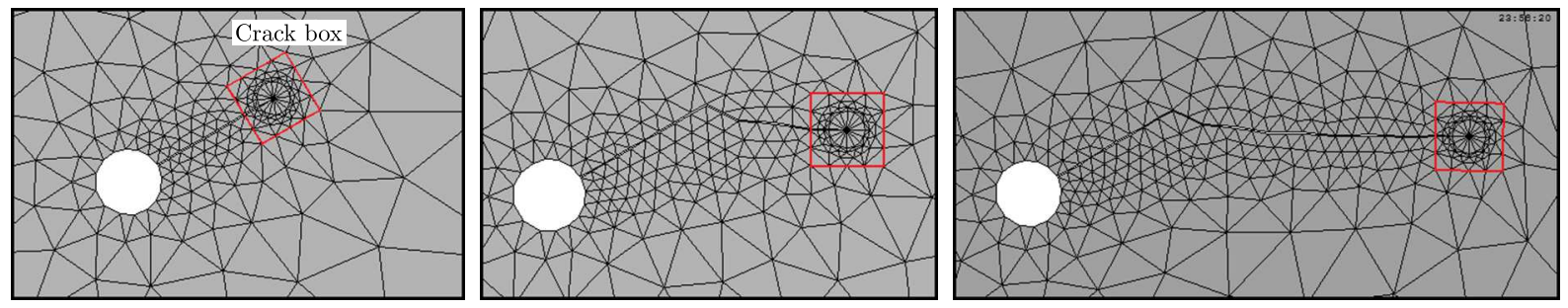

Fig. 9. Application of the crack box for automatic crack propagation

Using the present method, Fig. 10 shows examples of crack trajectories (for $\alpha=0^{\circ}$ and $180^{\circ}$ ) obtained by the numerical simulation. Figure 11 shows the crack growth trajectories for several initial inclination angles $\left(\alpha=0^{\circ}, 180^{\circ}, 30^{\circ},-30^{\circ}, 150^{\circ}\right.$ and $\left.-150^{\circ}\right)$. The obtained propagation path shows that the two crack propagations for $\left(\alpha=30^{\circ}\right.$ and $\left.-30^{\circ}\right)$, and for $\left(\alpha=150^{\circ}\right.$ and $-150^{\circ}$ ) are symmetric to the horizontal crack propagation for $\alpha=0^{\circ}$ (or $180^{\circ}$ ). The results obtained allow us to conclude that the criterion implemented gives a good crack path under mode I and mixed mode loadings.
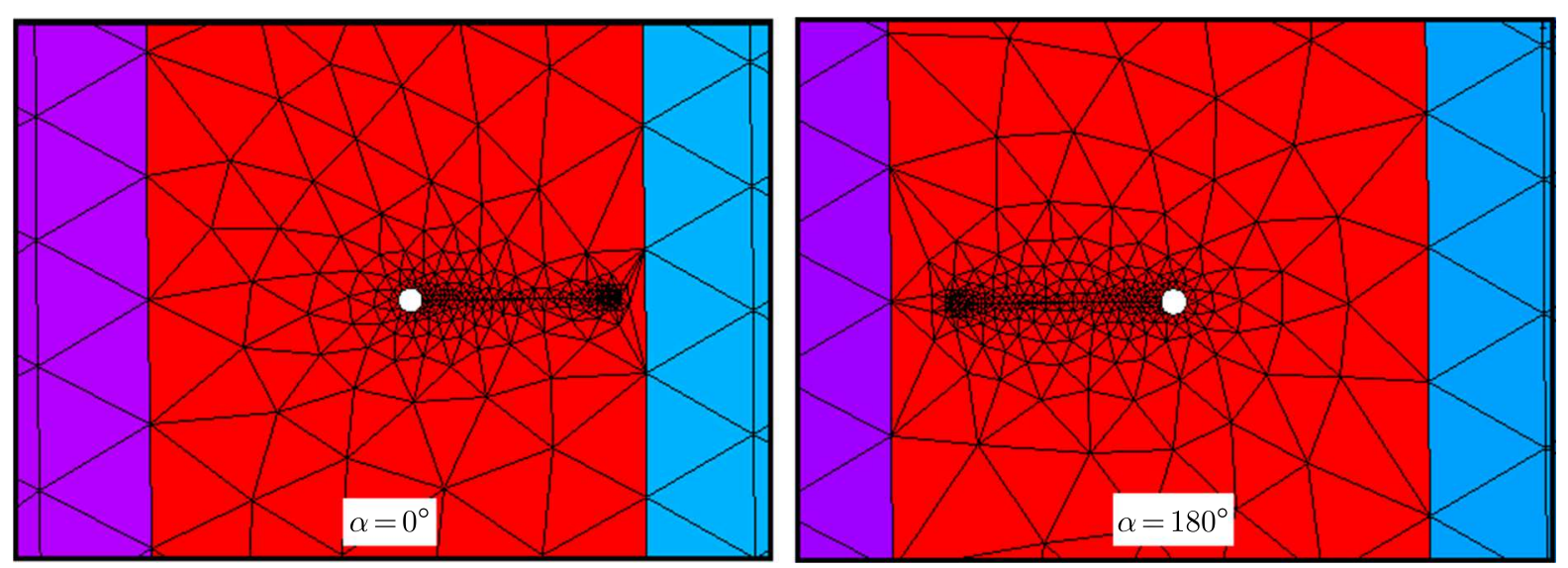

Fig. 10. Example of the crack propagation trajectory for $\alpha=0^{\circ}$ and $180^{\circ}$

To study the effect of the presence of a defect on the path of a crack, we considered a circular cavity of radius $r=2 R_{\text {cav }}$ located at a vertical distance $y=0.19 \mathrm{~mm}$ from the micro-void of radius $R_{\text {cav }}$ (Fig. 12a). Then, the cavity moves horizontally for three positions, as shown in Figs. 12b-12d.

Figure 12b shows the defect located at a vertical distance from the crack-tip. The position of this defect can modify the stress field in the vicinity of the crack and can influence the regulated propagation of the crack. Figures $12 \mathrm{c}$ and $12 \mathrm{~d}$ shows that the crack moves towards the second defect due to modification of the maximum main stress in the cement layer. This modification is due to the existence of the defect that will attract the crack. Then the crack moves in mode I away from the defect. These observations correspond to those obtained in (Benouis et al., 2015; Boulenouar et al., 2015; Benbarek et al., 2013) for crack growth path in the cement mantle of the reconstructed acetabulum. 

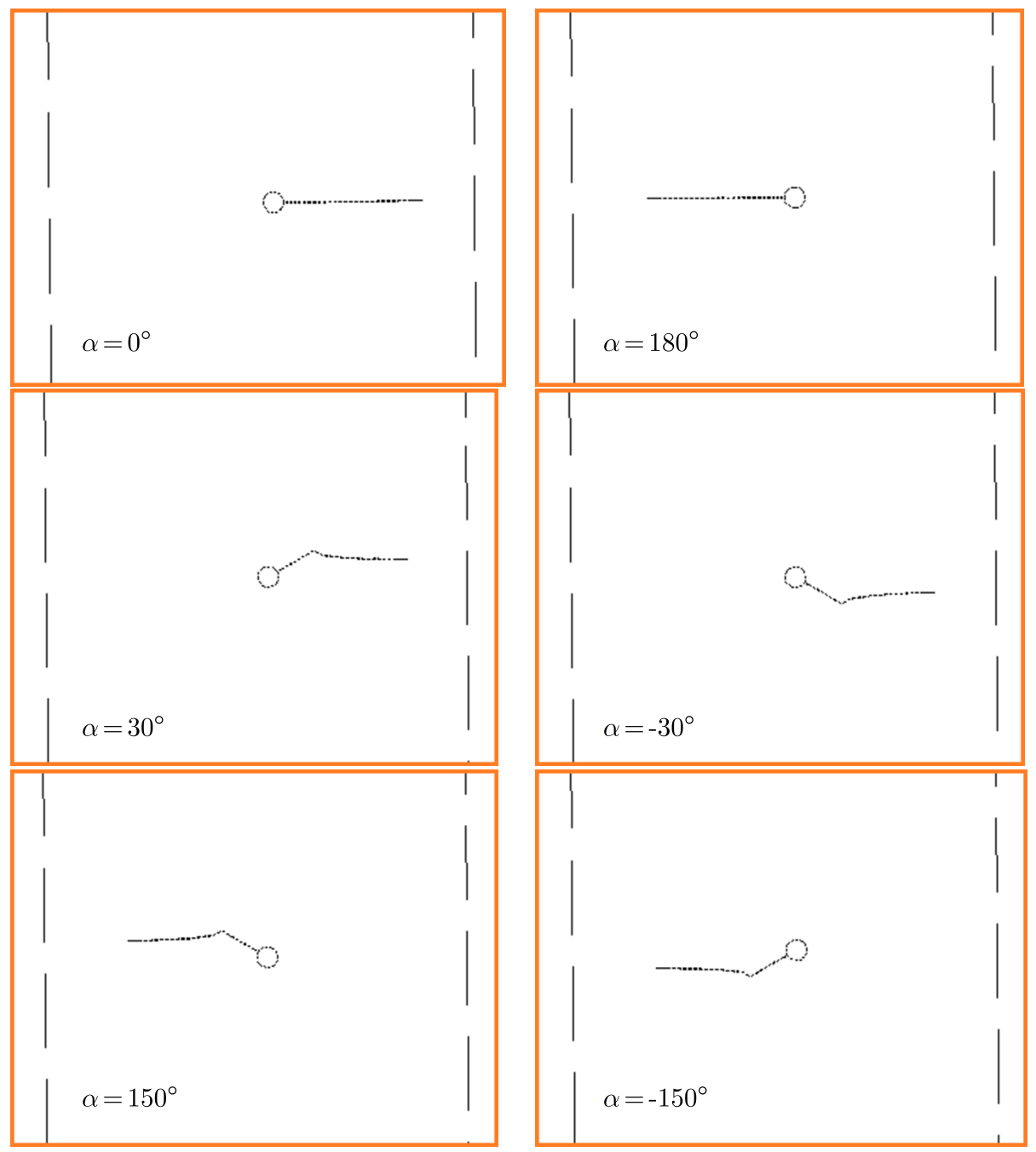

Fig. 11. Final crack propagation trajectory for: $\alpha=0^{\circ}, 180^{\circ}, 30^{\circ},-30^{\circ}, 150^{\circ}$ and $-150^{\circ}$

(a)

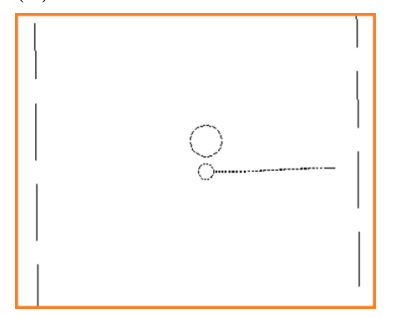

(b)

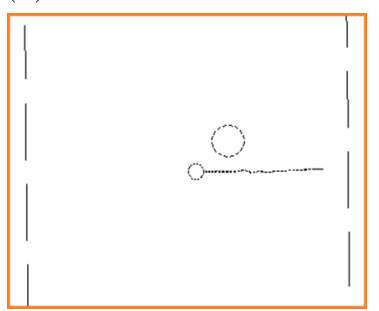

(c)

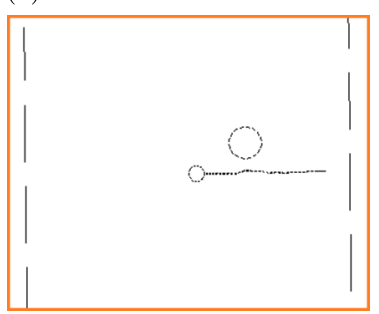

(d)

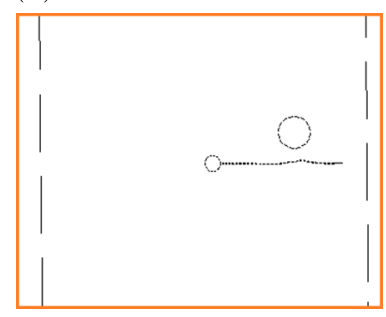

Fig. 12. Effect of the cavities on the crack propagation trajectory

\section{Conclusions}

In this paper, quarter-point singular elements around the crack tip are used to consider the singularity of stress and deformation fields at the crack tip in cement of the mantle of the total hip replacement.

The displacement correlation method is employed to determine the SIFs and to predict then the final crack trajectory by evaluation, in each propagation step, the crack direction using the maximum circumferential stress approach.

The crack box technique has been introduced in the FE code. The advantage of this technique is facilitation of the automatic remeshing of the structure during crack propagation. 
Numerical calculations made by FEM have shown that the integrated model can correctly describe the stress and deformation field near the crack tip by evaluating the SIFs, and the results are very acceptable for crack propagation in biomechanics fracture problems.

The good trajectory of the crack under mixed mode conditions is dependent on the crack increment length. As this distance is small, then it is closer to the exact solution. In the cement layer of the exterior side of the femur, the crack position $Y=46.48 \mathrm{~mm}$ presents a risk of crack propagation under mode I loading $\left(K_{I}>0\right.$ and $\left.K_{I I}=0\right)$.

\section{References}

1. Achour T., 2006, Etude du comportement mécanique et en rupture d'une prothèse totale de hanche cimentée, Thèse de Doctorat, Université de Sidi Bel Abbes, Algérie

2. Achour T., Benbarek S., Belhouari M., Bachir Bouiadjra B., 2007, Analyse par la méthode des éléments finis du comportement en rupture du ciment de la cupule d'une P.T.H., 8ème Congrès de Mécanique du 17-20 Avril, El Jadida, Maroc

3. Achour T., Tabeti M.S.H., Bouziane M.M., Benbarek S., Bachir Bouiadjra B., ManKOUR A., 2010, Finite element analysis of interfacial crack behavior in cemented total hip arthroplasty, Computational Materials Science, 47, 672-677

4. ANSYS, Inc. Programmer's Manual for Mechnical APDL, Release 12.1, 2009

5. Bachir Bouiadjra B., Belarbi A., Benbarek S., Achour T., Serier B., 2007, FE analysis of the behaviour of microcracks in the cement mantle of reconstructed acetabulum in the total hip prosthesis, Computational Materials Science, 40, 485-491

6. Barsoum R.S., 1974, On the use of isoparametric finite element in linear fracture mechanics, International Journal for Numerical Methods in Engineering, 10, 25-37

7. Belhouari M., Achour T., Bachir Bouiadjra B., Serier B., 2007, Analyse par la méthode des éléments finis du comportement en rupture du ciment de l'implant fémoral, 18ème Congrès Français de Mécanique, Grenoble, France

8. Benamara N., Boulenouar A., Aminallah M., 2017a, Strain energy density prediction of mixed-mode crack propagation in functionally graded materials, Periodica Polytechnica Mechanical Engineering, 61, 1, 60-67

9. Benamara N., Boulenouar A., Aminallah M., Benseddiq N., 2017b, On the mixed-mode crack propagation in FGMs plates: comparison of different criteria, Structural Engineering and Mechanics, 615, 371-379

10. Benbarek S., Bachir Bouiadjra B., Bouziane M.M., Achour T., Serier B., 2013, Numerical analysis of the crack growth path in the cement mantle of the reconstructed acetabulum, Materials Science and Engineering C, 33, 543-549

11. Benbarek S., Bachir Bouiadjra B., Mankour A., Achour T., Serier B., 2009, Analysis of fracture behaviour of the cement mantle of reconstructed acetabulum, Computational Materials Science, 44, 1291-1295

12. Benouis A., Boulenouar A., Benseddiq N., Serier B., 2015, Numerical analysis of crack propagation in cement PMMA: application of SED approach, Structural Engineering and Mechanics, $\mathbf{5 5}, 1,93-109$

13. Benouis A., Boulenouar A., Serier B., 2016, Finite element analysis of the behaviour of a crack in the orthopedic cement, Journal of Theoretical and Applied Mechanics, 54, 277-284

14. Benouis A., Zagane M.E., Boulenouar A., Serier B., Belgherras M.E., 2018, 3D FE analysis of the elliptical cracks behaviour in orthopedic cement of the total hip prostheses, Journal of Theoretical and Applied Mechanics, 56, 3, 803-813, DOI: 10.15632/jtam-pl.56.3.803 
15. Bhambri, S.K., Gilbertson L.N., 1996, Micro mechanisms of fatigue crack initiation and propagation in bone cements, Journal of Biomedical Materials Research, 29, 233-237

16. Boulenouar A., Benouis A., Benseddiq N., 2016, Numerical modelling of crack propagation in cement PMMA: Comparison of different criteria, Materials Research, 19, 4, 846-855

17. Boulenouar A., Benouis A., Merzoug M., 2015, Application of strain energy density approach in biomechanics fracture problems, Actes de la 2ème Conférence Internationale de Mécanique (ICM'15), Constantine, Algérie

18. Boulenouar A., Benseddiq N., Mazari M., 2013a, Strain energy density prediction of crack propagation for 2D linear elastic materials, Theoretical and Applied Fracture Mechanics, 67-68, $29-37$

19. Boulenouar A., Benseddiq N., Mazari M., 2013b, Two-dimensional numerical estimation of stress intensity factors and crack propagation in linear elastic analysis, Engineering, Technology and Applied Science Research, 3, 506-510

20. Boulenouar A., Benseddiq N., Mazari M., Benamara N., 2014, FE model for linear elastic mixed mode loading: estimation of SIFs and crack propagation, Journal of Theoretical and Applied Mechanics, 52, 373-383

21. Bouziane M.M., Bachir Bouiadjra B., Benseddiq N., Tabeti E.M.H., Serier B., BenbaREK S., 2013, The Effects of Cracks Emanating from Micro-Void and Bone Inclusion in Cemented Total Hip Replacement, Advances in Bio-Mechanical Systems and Materials, Advanced Structured Materials, Books, Springer

22. Erdogan F., Sin G.C., 1963, On the crack extension in plates under plane loading and transverse shear, Journal of Basic Engineering, 85, 519-527

23. Flitti A., Ouinas D., Bachir Bouindjra B., Benderdouche N., 2010, Effect of the crack position in the cement mantle on the fracture behaviour of the total hip prosthesis, Computational Materials Science, 49, 598-602

24. Griffith A.A., 1921, The phenomena of rupture and flow in solids, Philosophical Transactions of the Royal Society of London, Series A, 163-198

25. Hunga J.P., Chenb J.H., Chianga H.L., Shin J.S., 2004, Computer simulation on fatigue behavior of cemented hip prostheses: a physiological model, Computer Methods and Programs in Biomedicine, 76, 103-113

26. Kim B., Moon B., Mann K., Kim H., Boo K.-S., 2008, Simulated crack propagation in cemented total hip replacements, Materials Science and Engineering A, 483-484, 306-308

27. Kong X.M., Schluter N., Dahl W., 1995, Effect of triaxial stress on mixed mode-facture, Engineering Fracture Mechanics, 52, 2, 379-388

28. LEROY R., 1991, Etude et comportement non-uniforme de l'interface entre implant fémorale et liant polymérique dans le cas de prothèse totale de hanche, Thèse de doctorat, Université de Tours, France

29. Lim I.L., Johnston I.W., Choi S.K., 1992, Comparison between various displacement-based stress intensity factor computation techniques, International Journal of Fracture, 58, 193-210

30. McCormack B.A.O., Prendergast P.J., 1999, Micro damage accumulation in the cement layer of hip replacements under flexural loading, Journal of Biomechanics, 32, 467-475

31. Oshkour A.A., Davoodi M.M., Abu Osman N.A., Yau Y.H., Tarlochan F., Wan Abas WA.B., 2013, Finite element analysis of circumferential crack behavior in cement-femoral prosthesis interface, Materials and Design, 49, 96-102

32. Ouinas D., Flitti A., Sahnoun M., Benbarek S., Taghezout N., 2012, Fracture behavior of the cement mantle of reconstructed acetabulum in the presence of a microcrack emanating from a microvoid, International Journal of Materials Engineering, 2, 90-104 
33. RicE J.R., 1986, A path independent integral and the approximate analysis of strain concentrations by notches and cracks, Journal of Applied Mechanics, 35, 379-386

34. Rybicki E.F, Kanninen M.F., 1977, Finite element calculation of stress intensity factors by a modified crack closure integral, Engineering Fracture Mechanics, 9, 931-938

35. Sahli A., Benbareka S., Wayneb S., Bachir Bouiadjra B., Serier B., 2014, 3D crack behavior in the orthopedic cement mantle of a total hip replacement, Applied Bionics and Biomechanics, 11, 135-147

36. Shin C., De Lorenzi H., German M., 1976, Crack extension modeling with singular quadratic isoparametric elements, International Journal of Fracture, 12, 647-651

37. Siн G.C., 1973, Some basic problems in fracture mechanics and new concepts, Engineering Fracture Mechanics, 5, 365-377

38. SiH G.C., 1974, Strain energy density factor applied to mixed mode crack problems, International Journal of Fracture, 10, 3, 305-321

39. Taylor D., Hazenberg J.G., Lee T.C., 2003, The cellular transducer in damage-stimulated bone remodelling: a theoretical investigation using fracture mechanics, Journal of Theoretical Biology, 225, 65-75

40. Theocaris P.S., Andrianopoulos N.P., 1982a, The Mises elastic-plastic boundary as the core region in fracture criteria, Engineering Fracture Mechanics, 16, 425-432

41. Theocaris P.S., Andrianopoulos N.P., 1982b, The T-criterion applied to ductile fracture, International Journal of Fracture, 20, 125-130 